\title{
THE INFLUENCE OF FOREIGN STATES ON THE ACTIVITIES OF EXTREMIST ORGANISATIONS IN THE SOUTH OF RUSSIA ${ }^{1}$
}

\author{
Anton V. Bredikhin \\ Center of Security Studies, RAS, Moscow, Russian Federation
}

\begin{abstract}
Introduction. The problem of the spread of extremist organizations' activities in the South of Russia is intensified due to the increasing role of international actors and the influence of neighboring States. Extremist groups are included in the sphere of interests of countries with high level of institutional instability that have unresolved territorial administrative problems and also major terrorist organizations such as the 'Islamic State' (ISIL) prohibited on the territory of the Russian Federation. Methods. The author applies an institutional method to determine the role of international influence on the development of extremist organizations in the South of Russia. Analysis. Despite the decline in its activity, the ISIL continues to be among the priority threats to international security. The Russian Federation has successfully conducted anti-terrorist operation in Syria, while the ISIL operates in Iraq and other regions of the world. Its area of interest includes Russia, since the ISIL units exist on the territory of the Caucasus region and the Crimean Peninsula. At the same time, the territory of the Rostov region and the Republic of Crimea are subjected to the influence of the Ukrainian geo-strategic interests. The Ukrainian authorities act with territorial claims to the Russian Federation on a number of border regions as well as organize sabotage operations and support marginal movements. The so-called 'Circassian question' continues to be significant for the South of Russia. In the context of the present research, the author poses the problem of considering the interaction of neighboring countries and extremist organizations in the Russian border regions. The institutional research approaches allow determining the main "point of tension" in the southern border area, and to identify the main actors influencing the extremist organization. Results. The results of the work give conclusions about the main directions of foreign States' influence on the regions of the South of Russia and counteraction to them by the security authorities.
\end{abstract}

Key words: 'Islamic State', the border region, terrorism, extremism, the South of Russia.

Citation. Bredikhin A.V. The Influence of Foreign States on the Activities of Extremist Organisations in the South of Russia. Vestnik Volgogradskogo gosudarstvennogo universiteta. Seriya 4, Istoriya. Regionovedenie. Mezhdunarodnye otnosheniya [Science Journal of Volgograd State University. History. Area Studies. International Relations], 2019, vol. 24, no. 1, pp. 216-224. (in Russian). DOI: https://doi.org/10.15688/jvolsu4.2019.1.19

\section{ВЛИЯНИЕ ИНОСТРАННЫХ ГОСУДАРСТВ НА ДЕЯТЕЛЬНОСТЬ ЭКСТРЕМИСТСКИХ ОРГАНИЗАЦИЙ ЮГА РОССИИ ${ }^{1}$}

\author{
Антон Викторович Бредихин
}

Центр исследования проблем безопасности РАН, г. Москва, Российская Федерация

Аннотация. Проблема распространения деятельности экстремистских организаций на Юге России актуализируется ввиду усиления роли международных акторов, влияния соседних государств. Экстремист- 
ские группировки входят в сферу интересов стран с высоким уровнем институциональной нестабильности, имеющих неразрешенные административно-территориальные проблемы, а также крупных террористических организаций, таких как запрещенное на территории Российской Федерации «Исламское государство». Несмотря на снижение своей активности, ИГ продолжает оставаться в числе первоочередных угроз международной безопасности. Российская Федерация успешно провела антитеррористическую операцию в Сирии, в то же время ИГ ведет свою работу на территории Ирака и ряда других регионов мира. В сферу его интересов входит и Россия, так как подразделения ИГ существуют на территории Кавказского региона и Крымского полуострова. В то же время территории Ростовской области и Республики Крым подвержены влиянию украинских геостратегических интересов. Украинские власти выступают с территориальными претензиями к Российской Федерации по ряду приграничных регионов, а также организовывают диверсионные операции, поддерживают маргинальные движения. Значимым для Юга России продолжает оставаться и так называемый «черкесский вопрос». В рамках работы автор ставит проблему рассмотрения взаимодействия сопредельных стран и экстремистских организаций в приграничных российских регионах. Используется институциональный исследовательский подход, что позволяет определить основные «точки напряженности» в системе южнороссийского приграничья и выявить главные акторы, оказывающие влияние на экстремистские организации. В результатах работы приводятся выводы об основных направлениях влияния иностранных государств на регионы Юга России и противодействия им со стороны органов безопасности.

Ключевые слова: «Исламское государство», приграничье, терроризм, экстремизм, Юг России.

Цитирование. Бредихин А. В. Влияние иностранных государств на деятельность экстремистских организаций Юга России // Вестник Волгоградского государственного университета. Серия 4, История. Регионоведение. Международные отношения. - 2019. - Т. 24, № 1. - С. 216-224. - DOI: https://doi.org/10.15688/ jvolsu4.2019.1.19

Введение. Современное российское общество стоит на пути формирования единой российской нации, объединяющей и в то же время обогащающей этнокультурные особенности народов Российской Федерации. Процесс ее формирования подкреплен Стратегией государственной национальной политики Российской Федерации на период до 2025 г., Стратегией развития государственной политики Российской Федерации в отношении российского казачества до 2020 г., Стратегией национальной безопасности Российской Федерации. На их реализацию направлен ряд федеральных, региональных и муниципальных программ развития.

В то же время вопрос о сепаратистских и экстремистских тенденциях в субъектах Российской Федерации оказывается в числе первоочередных во внутриполитической повестке дня. Особенно он значим для регионов, имеющих сложный полиэтнический и поликонфессиональный характер. В частности, для субъектов Южного и Северо-Кавказского федеральных округов. Идеи «парада суверенитетов» 1990-х гг., наведение конституционного порядка на территории Чеченской республики, осетино-ингушский конфликт, формирование сети террористического бандподполья и сегодня оказываются в числе проблем, вы- зывающих интерес у внешних акторов, стремящихся дестабилизировать ситуацию на Юге России.

Целью исследования становится рассмотрение проблемы влияния сопредельных стран, а также контролируемых ими международных объединений на экстремистские организации Юга России.

В рамках исследования предполагается решить следующие задачи:

- провести анализ влияния руководства Грузии на актуализацию проблемы так называемого «черкесского вопроса»;

- выявить влияние экстремистских организаций, действующих на территории Украины, на приграничные регионы Юга России;

- рассмотреть влияние наиболее значимой международной террористической организации «Исламского государства» на Юге России.

Методы. В рамках исследования используется институциональная методология, позволяющая определить роль международного влияния на развитие экстремистских организаций Юга России. Данный вопрос находится в сфере научного дискурса ряда ученых. Анализируя последние работы исследователей, в частности, можно отметить, что проблемы влияния экстремистских и терро- 
ристических организаций («Исламское государство», «Правый сектор», «Меджлис крымско-татарского народа») на регионы Юга России рассматривают Г.Г. Матишов, Д.Г. Котеленко [10], И.В. Пащенко [14], Е.М. Поляков [16], А.А. Токарев [18], А.А. Ярлыкапов [19]. Аспекты информационной деятельности экстремистских организаций затрагивают И.Ю. Сундиев, А.А. Смирнов, В.Н. Костин [17]. Роль ИГ в системе международной безопасности определяют исследователи Российского института стратегических исследований в коллективном труде «ИГИЛ как угроза международной безопасности» [7].

Анализ. Проблемы дестабилизации ситуации на российском Кавказе. Операция по принуждению к миру Грузии в 2008 г. и последующее признание независимости Республики Абхазия и Республики Южная Осетия-Алания Российской Федерацией выступили, с одной стороны, шагом на пути к безопасности в регионе Северо-Западного Кавказа, где грузинские военные и политические круги, начиная со времен СССР, проводили политику этноцида в отношении абхазского и осетинского населения. С другой стороны, усилились антироссийские тенденции грузинского руководства, решившего воспользоваться в преддверии проведения в 2014 г. XXII Зимних Олимпийских игр в Сочи проблематикой так называемого «черкесского вопроса».

В 2011 г. после продолжительной работы грузинский парламент принял резолюцию о признании геноцида черкесов со стороны Российской империи после окончания Кавказской войны (1817-1864 годы). Единогласное голосование должно было, по мнению некоторых депутатов, не только восстановить так называемую «историческую справедливость», но и открыть «ящик Пандоры», потому как никакого плана действий грузинское руководство не имело [9]. Однако данное решение способствовало актуализации в информационном пространстве того факта, что место проведения XXII Зимних Олимпийских игр является территорией исторического проживания черкесов, на чем пытались спекулировать представители ряда маргинальных черкесских организаций, имеющих антироссийскую направленность.
Дальнейшие действия грузинских властей призывали бойкотировать Олимпийские игры, ставили задачу саботировать участие в них команд Абхазии и Южной Осетии-Алании, формировали активную антироссийскую риторику в информационной повестке Европейского Союза и США. Решение грузинского парламента было благоприятно воспринято представителями черкесского движения «Адыгэ Хасэ», выступающего с последовательной позицией признания так называемого «черкесского вопроса». Уже в 2014 г. ряд черкесских активистов обратились с просьбой признания геноцида черкесов к Верховной Раде Украины, получив благоприятный отклик со стороны радикально настроенных народных депутатов Украины, в том числе известного своими антироссийскими заявлениями О.В. Ляшко.

В то же время при проведении Олимпиады черкесы были представлены как коренной народ, проживающий на Черноморском побережье Краснодарского края, черкесская этнокультурная составляющая была включена в программу открытия и закрытия игр, в Олимпийской деревне был создан «Домик черкеса», где многочисленные туристы со всего мира могли наблюдать за традиционным бытом шапсугов, одного из субэтносов адыгейцев. В этом приняла участие большая делегация зарубежных адыгов, высоко оценивших уровень подготовки к спортивным соревнованиям, а ряд общественных объединений черкесов Краснодарского края выступил с позиции поддержки Олимпийских игр.

«Черкесский вопрос» является значимым и для запрещенной в Российской Федерации организации «Исламское государство». В частности, ранее его представители заявляли о возможности создания на территории Краснодарского края и Адыгеи «Черкесии» в составе «Вилайета Кавказ» или «Вилайета Ногай», ориентируясь на ногайский народ, не имеющий своего единого национально-территориального образования [8]. Особую роль данные заявления приобретают на фоне активизации вербовочной деятельности «Исламского государства» на территории Ахметского муниципалитета Грузии (Панкисского ущелья), где среди чеченцев-кистинцев, еще с образования так называемой «Ичкерии», начал активно распространятся ваххабизм. Так, в 
1995 г. в ущелье приехал первый арабский мулла-ваххабит, получивший из Саудовской Аравии значительную финансовую поддержку.

Ваххабизм в Панкиси распространился в основном среди местной молодежи, и это стало серьезной проблемой между поколениями. Эксперт по вопросам Кавказа Мамука Арешидзе в интервью газете «Квирис палитра» назвал это «религиозным мини-противостоянием». По его словам, традиционный ислам в Панкиси исповедуют в основном пожилые люди. У них нет ни сил, ни средств противостоять распространению идеологии ваххабизма [5]. За последние годы роль общины только усилилась. Все активнее начали строиться мечети, где проповедуют муллы ваххабитского толка. Чаще стали возникать и конфликты между грузинами и чеченцами.

В террористической организации «Панкисский джамаат», расположенной в одноименном регионе Грузии в период правления Михаила Саакашвили, было создано «Правительство Чеченской Республики Ичкерия в изгнании», осуществляющее террористические акты на Северном Кавказе Российской Федерации. Однако деятельность грузинских мусульманских радикалов не ограничивается исключительно территорией Кавказа. Грузия уже давно включена в орбиту «арабского мира», и ИГ является тому подтверждением. Так, правой рукой лидера террориста Абу Бакра Аль-Багдади выступал Абу Умар Аш-Шишани (с арабского - Умар Чеченский, настоящее имя Тархан Батирашвили; родился в ауле Биркиани Ахметского муниципалитета Грузии).

Проблема вербовки молодого населения и распространения экстремистской идеологии «Исламского государства» свойственна и соседнему азербайджано-дагестанскому приграничью. Из Азербайджана, начиная с 2012 г., в «Исламское государство» каждый год направляются сотни боевиков. Общая численность азербайджанцев в рядах ИГ составляет более полутора тысяч человек. По данным Министерства внутренних дел Турции, опубликованным в докладе «Борьба Турции против ИГИЛ», 1677 азербайджанцам запрещен въезд на турецкую территорию изза их симпатий «Исламскому государству» [11]. Салафиты активно проводят работу в северных районах страны, населенных преимущественно суннитами (аварцами и лезгинами). Их активность направлена в том числе и на формирование очагов нестабильности боевиками ИГ в соседнем российском Дагестане [3, с. 485].

По данным доклада коммуникационного холдинга Minchenko Consulting, причиной нестабильности в Азербайджане выступает «нарастающий хаос к югу от старой советской границы на всем ее протяжении, где укрепляются позиции ИГ и наблюдается экспорт исламистских настроений» [12]. На карте мира, опубликованной боевиками, Азербайджан входит в состав исламского халифата, к созданию которого обращена пропаганда связанных с террористами медиаресурсов. В это же время соседний Дагестан является регионом, в котором вербовщики «Исламского государства» используют потенциал террористических группировок, ведущих деятельность с 1990-х гг. и вовлекающих в свои ряды молодежь в горных районах республики.

Роль украинского фактора. «Евромайдан» 2013-2014 гг., последовавшая за ним волна гражданского протеста «Русская весна», возвращение Крымского полуострова в состав Российской Федерации, самопровозглашение независимости Донецкой и Луганской народных республик, а следом и начало вооруженного противостояния в Донбассе способствовали созданию «очага напряжения» у западных границ Юга России, фактически придав Ростовской области статус «прифронтового региона». Она имеет длительные исторические связи с Донбассом, в частности, современные территории ДНР и ЛНР располагаются на дореволюционных землях Области войска Донского, и значимые экономические взаимоотношения, чему способствовал созданный в 2010 г. еврорегион «Донбасс».

Существует точка зрения, что пожары, уничтожившие в 2017 г. историческую часть Ростова-на-Дону и лесные массивы Усть-Донецкого района Ростовской области, были организованы украинской стороной [15]. Ответственность за их организацию взяли неоязычники из украинских националистических организаций, что, однако, не подтверждено российскими властями, а, как и любая террористическая организация украинских националистов, воюющих в Донбассе, они способны 
приписывать себе действия, которые сами не совершали [13].

Деятельность украинских агитаторов нашла отклик в среде радикально настроенных представителей казачьего движения. Идеи создания Донской казачьей республики имели место с момента распада СССР, и конфликт в Донбассе выступил точкой активизации подобных организаций. Несмотря на то что большая часть донского казачества воевала на стороне ополчения Новороссии, маргиналы, ранее неоднократно критиковавшие российские власти, отправились на территорию Украины и сформировали подобие «казачьей политической эмиграции» (как они сами себя называют). В их числе оказался и казак-маргинал Сергей Лошкарев (Белогвардеец), призывавший народного депутата Верховной Рады Украины Д.А. Яроша ввести подразделения «Правого сектора» на территорию Дона и, в частности, столицы донского и мирового казачества - г. Новочеркасск [1].

Украинские власти обещали донским казакам возможность образования казачьей армии, политических центров, однако обещаний не сдержали. При этом украинская бюрократическая система не особо принимала новых «политических беженцев»: «Казаки, с их тяготением к государственности, “не в чести” у олигархической властной верхушки Украины. Многие из тех, кто приехал сюда из России, Белоруссии, Грузии отстаивать независимость Украины, сейчас ходят под Дамокловым мечом депортации на родину со всеми вытекающими...», - считает представитель украинского казачества. При этом казаковпредателей активно принимают такие националистические организации, как «Правый сектор», и используют их на передовой в качестве «мяса» [6].

Активна украинская внешняя политика и в отношении Крымского полуострова, где в качестве возможного союзника рассматривается «Исламское государство». На Крымском полуострове ИГ получило базу в виде «Меджлиса крымско-татарского народа» и организаций ему союзных: «Аль-Раид», «Хизбут-Тахрир аль-Ислами» и др. Соответственно, в рядах «Исламского государства» воюет бандформирование «Крымский джамаат», состоящее из крымских татар. Одним из организаторов исламистских батальонов на территории Херсонской области выступает представитель Меджлиса Л.Э. Ислямов, который в период 02.04-28.05.2014 г. занимал пост вице-премьера крымского правительства [2].

Деятельность ИГ в Крыму активизируется ввиду лоялизма радикалам со стороны соседней Украины и желанию официального Киева использовать их для дезинтеграции полуострова от Российской Федерации. В этих целях территория соседней Херсонской области рассматривается в качестве будущей крымско-татарской автономии. В южных районах области присутствуют арабские и турецкие наемники, которые представляют союзные ИГ организации, а по некоторым данным создали свои тренировочные базы. «Нас крайне беспокоит, что украинская сторона в обмен на антироссийские акции позволяет исламским радикалам участвовать в Херсонской области в противоправных действиях и формировать параллельные структуры власти», - считает депутат Государственной Думы Российской Федерации Р.И. Бальбек [8].

Опасения крымского депутата основываются, прежде всего, на том, что в период нахождения Крыма в составе Украины на территории полуострова вел широкую деятельность ряд организаций исламистов. В конце 90-х гг. ХХ в. руководство Меджлиса крымскотатарского народа совместно с Духовным Управлением Мусульман Крыма существенно расширило связи с арабскими организациями. Влияние арабских государств на религиозную жизнь мусульман Крыма осуществлялось через межобластную организацию «АльРаид», фонды «Зам-зам», «Крым-2000» и Бирлик. Это привело к усилению турецко-арабского соперничества за влияние на Крымском полуострове. Традиционно протурецкая панэтническая ориентация Меджлиса заставила его признавать монопольную роль Турции в процессе реконструкции ислама в Крыму. Однако отвергать по этому поводу сильные финансовые потоки со стороны Саудовской Аравии и других арабских стран было бы недальновидно и непродуктивно. Результатом этого и выступила арабская экономическая экспансия в Крыму [4, с. 40].

Проблема распространения «Исламского государства». Приграничные регионы 
Южного и Северо-Кавказского федеральных округов объединяет проблема деятельности «Исламского государства» на сопредельных территориях. Его распространение происходит в среде исламистских и маргинальных групп, использующих институциональную нестабильность, слабость Центра, наличие вооруженного противостояния для формирования своих идеологических и учебно-тренировочных объектов. По аналогии происходило развитие событий на Ближнем Востоке.

Возникшее на территории Ирака в 1999 г. как «Джамаат ат-Таухид валь-Джихад», ИГ в 2006 г. высказало свои претензии на всю территорию Ирака, получив название «Исламское государство Ирак», со временем распространив свое влияние на сопредельные районы Сирии. Появление и быстрое развитие ИГ сопряжено с падением режима Саддама Хусейна и неспособностью проамериканского иракского руководства обеспечить полноценный контроль за территорией Ирака. Вместе с тем ИГ получило контроль над нефтяными месторождениями, чем выгодно отличилось от «Аль-Каиды», одним из основных источников доходов которой являлась наркоторговля. Торговля нефтью ИГ осуществлялась нелегально через приграничные районы Турции. Не менее значимыми путями пополнения бюджета для данной организации стала торговля заложниками, рабами, наркотиками.

Проведение в 2015-2017 гг. российскими военными операции в Сирии способствовало уничтожению представителей ИГ на сирийской территории. Однако за это время исламистами было объявлено о начале «джихада» против России, в результате чего были спланированы и разработаны теракты в Москве, регионах Кавказа, Поволжья. Их реализаторами выступили в том числе и боевики, направившиеся ранее в ряды «Исламского государства» из российских регионов, а также представители республик Средней Азии.

В соответствии со Стратегией национальной безопасности Российской Федерации до 2020 г., наряду с сохраняющимися очагами напряженности на Ближнем и Среднем Востоке, в Африке, Южной Азии, на Корейском полуострове появляются новые «горячие точки», становящиеся базой для распространения терроризма, межнациональной розни, религиозной вражды, иных проявлений экстремизма. ИГ расширяет свое влияние на регионы Российской Федерации, используя уже существующую базу и получая неформальную поддержку от международных акторов. Важной в данном плане выступает проблема использования информационных и коммуникационных ресурсов в качестве проводников идеологии экстремистских организаций.

Результаты. На основании изложенного выделим следующие тенденции.

Во-первых, правительство Грузии периода президентства М.Н. Саакашвили оказывало активную поддержку черкесам, актуализировало проблематику так называемого «геноцида». Данная тенденция наиболее активно проявилась в период проведения XXII Зимних Олимпийских игр в г. Сочи. В это время Российской Федерацией была проведена значительная работа по привлечению «зарубежных» черкесов к подготовке Олимпиады, осуществлена качественная информационная политика на международной арене. После 2014 г. «черкесский вопрос» в Грузии теряет актуальность и в настоящее время не наблюдается его широкой поддержки.

Во-вторых, правительство Украины периода президентства П.А. Порошенко проводит значительную работу по поддержке экстремистских организаций националистической направленности в приграничных субъектах Российской Федерации (Ростовская область, Республика Крым, Краснодарский край). Основной целью деятельности выступает дестабилизация российско-украинского приграничья, развитие сепаратизма и национализма. Органами безопасности России предпринимаются меры по предотвращению терактов в приграничных регионах, а также снижению уровня радикализма среди населения.

В-третьих, «Исламское Государство» расширяет сферу своего влияния не только посредством имеющихся проповедников и существовавших ранее террористических организаций на Кавказе и в Крыму, но и посредством возвращающихся из Сирии бывших боевиков. Пропаганда радикального ислама в совокупности с террористической деятельностью выступают ответом ИГ на военные победы Российской Федерации на Ближнем Востоке. Текущая деятельность требует расши- 
рения числа мер по пресечению увеличения членов ИГ со стороны не только органов безопасности, но и мусульманских организаций Юга России.

\section{ПРИМЕЧАНИЕ}

1 Статья подготовлена при финансовой поддержке Российского научного фонда (проект № 17 68-00001 «Влияние институциональной нестабильности сопредельных стран на деятельность экстремистских организаций Юга России»). ФГБУН Центр исследования проблем безопасности Российской академии наук.

\section{СПИСОК ЛИТЕРАТУРЫ}

1. Бандеровец из рощи. - Электрон. текстовые дан. - Режим доступа: https://ovdinfo.org/ articles/2014/06/15/banderovec-iz-roshchi (дата обращения: 30.09.2017). - Загл. с экрана.

2. «Батальон меджлиса» погубили дрязги лидеров // Взгляд. - Электрон. текстовые дан. - Режим доступа: https:/vz.ru/politics/2017/2/13/857775.html (дата обращения: 28.12.2017). - Загл. с экрана.

3. Бредихин, А. В. Исламское государство и Евразийский Экономический Союз: азербайджанский плацдарм / А. В. Бредихин // Социокультурный аспект евразийской интеграции. Евразийский Гражданский Альянс : сб. науч. ст. / науч. ред. Л. А. Василенко. - Белгород : Изд-во БелГУ, 2017. - С. 484-491.

4. Бредихин, А. В. Крымскотатарский вопрос во внешней политике украинских властей (2014 2017 гг.) / А. В. Бредихин // Россия и новые государства Евразии. - 2017. - № 4. - С. 37-47.

5. В Панкиси ваххабизм готовится к войне // Georgia Times. - Электрон. текстовые дан. - Режим доступа: http://www.georgiatimes.info/articles/39091.htm (дата обращения: 28.12.2017). - Загл. с экрана.

6. Жизнь казаков-эмигрантов из РФ в Украине. - Электрон. текстовые дан. - Режим доступа: http://nr2.lt/blogs/Alexander_Dzikovitsky/ZHiznkazakov-emigrantov-iz-RF-v-Ukraine-125515.html (дата обращения: 30.09.2017). - Загл. с экрана.

7. ИГИЛ как угроза международной безопасности / под ред. А. В. Глазовой. - М. : Изд-во РИСИ, 2015. $-188 \mathrm{c}$.

8. ИГИЛ нацелилось на Крым // Свободная пресса. - Электрон. текстовые дан. - Режим доступа: http://svpressa.ru/politic/article/153461/ (дата обращения: 12.02.2017). - Загл. с экрана.

9. Как черкесы восприняли решение парламента Грузии признать геноцид черкесского наро- да // Радио Свобода. - Электрон. текстовые дан. - Режим доступа: https://www.svoboda.org/a/24214015.html (дата обращения: 28.12.2017). - Загл. с экрана.

10. Матишов, Г. Г. Украинские националисты на страже американских интересов / Г. Г. Матишов, Д. Г. Котеленко // Власть. - 2016. - № 12. С. 211-222.

11. МВД Турции опубликовало данные о боевиках ИГ из Азербайджана. - Электрон. текстовые дан. - Режим доступа: http://verelq.am/ru/ node/20324 (дата обращения: 28.12.2017). - Загл. с экрана.

12. «Минченко консалтинг» представил доклад по проблемам стран Южного Кавказа // Газета.ру. - Электрон. текстовые дан. - Режим доступа: https://www.gazeta.ru/politics/2015/08/ 18_a_7694735.shtml (дата обращения: 28.12.2017). Загл. с экрана.

13. Ответственность за поджог в Ростове взяли на себя неоязычники с Украины // ИА REGNUM. Электрон. текстовые дан. - Режим доступа: https:// regnum.ru/news/2315581.html (дата обращения: 30.09.2017). - Загл. с экрана.

14. Пащенко, И. В. «Исламское государство» и радикально-исламистские силы на Северном Кавказе: новые угрозы национальной безопасности Российской Федерации / И. В. Пащенко // Глобальные вызовы современности и проблемы устойчивого развития Юга России : материалы Междунар. науч-практ. конф. - Нальчик : Изд-во КБНЦ РАН, 2015. - C. $44-47$.

15. Пожар в Ростове-на-Дону устроили украинские диверсанты // Московский комсомолец. Электрон. текстовые дан. - Режим доступа: https://www.kp.ru/daily/26721/3747259/ (дата обращения: 30.09.2017). - Загл. с экрана.

16. Поляков, Е. М. «Исламское государство» (ИГИЛ) как детерминант политического насилия на Северном Кавказе / Е. М. Поляков // Панорама. 2015. - № 19. - С. 73-78.

17. Сундиев, И. Ю. Информационно-пропагандистская деятельность террористической организации «Исламское государство Ирака и Леванта» / И. Ю. Сундиев, А. А. Смирнов, В.Н.Костин // Библиотека криминалиста. Научный журнал. 2015. - № 1 (18). - С. 208-218.

18. Токарев, А. А. Институционализация украинского национализма: идеологические различия между партиями «Свобода» и «Правый сектор» / А. А. Токарев // Вестник МГИМО университета. - 2014. - № 6 (39). - С. 144-152.

19. Ярлыкапов, А. А. «Исламское государство» (ИГ): вызовы для Юга России / А. А. Ярлыкапов // Религия и политика на Юге России: аспекты взаимодействия. - М. : Научное общество кавказоведов, 2015. - С. 78-97. 


\section{REFERENCES}

1. Banderovets iz roshchi [Banderovets from the Grove]. URL: https://ovdinfo.org/articles/2014/ 06/15/banderovec-iz-roshchi (accessed 30 September 2017).

2. «Batalyon medzhlisa» pogubili dryazgi liderov ["Battalion of the Majlis" Killed Squabbling Leaders]. Vzglyad. URL: https://vz.ru/politics/2017/2/ 13/857775.html (accessed 28 December 2017).

3. Bredikhin A.V. Islamskoe gosudarstvo i Evraziyskiy Ekonomicheskiy Soyuz: azerbaydzhanskiy platsdarm [The Islamic State and the Eurasian Economic Union: Azerbaijan is a Springboard]. Sotsiokulturnyy aspekt evraziyskoy integratsii. Evraziyskiy Grazhdanskiy Alyans: sb. nauch. st. [Sociocultural Dimension of Eurasian Integration. Eurasian Civil War: Collection of Scientific Articles]. Belgorod, Izd-vo BelGU, 2017, pp. 484-491.

4. Bredikhin A.V. Krymskotatarskiy vopros vo vneshney politike ukrainskikh vlastey (2014-2017 gg.) [The Crimean Tatar issue in the foreign policy of the Ukrainian authorities (2014-2017)]. Rossiya i novye gosudarstva Evrazii [Russia and New States of Eurasia], 2017, no. 4, pp. 37-47.

5. V Pankisi vakhkhabizm gotovitsya k voyne [In Pankisi Wahhabism Is Preparing for War]. Georgia Times. URL: http://www.georgiatimes.info/articles/ 39091.htm (accessed 28 December 2017).

6. Zhizn kazakov-emigrantov iz RFv Ukraine [Life of Cossacks-Emigrants from Russia in Ukraine]. URL: http://nr2.1t/blogs/Alexander_Dzikovitsky/ ZHizn-kazakov-emigrantov-iz-R $\bar{F}$-v-Ukraine125515.html (accessed 30 September 2017).

7. Glazova A.V., ed. IGIL kak ugroza mezhdunarodnoy bezopasnosti [ISIS as a Threat to International Security]. Moscow, Izd-vo RISI, 2015. $188 \mathrm{p}$.

8. IGIL natselilos na Krym [ISIS Is Targeting Crimea]. Svobodnaya pressa [Free Press]. URL: http: //svpressa.ru/politic/article/153461/ (accessed 12 February 2017).

9. Kak cherkesy vospriniali reshenie parlamenta Gruzii priznat genotsid cherkesskogo naroda [As the Circassians Accepted the Decision of the Parliament of Georgia to Recognize the Circassian Genocide]. Radio Svoboda. URL: https:/ /www.svoboda.org/a/24214015.html (accessed 28 December 2017).

10. Matishov G.G., Kotelenko D.G. Ukrainskie natsionalisty na strazhe amerikanskikh interesov [Ukrainian Nationalists Guarding American Interests]. Vlast [Power], 2016, no. 12, pp. 211-222.

11. MVD Turtsii opublikovalo dannye o boevikakh IG iz Azerbaydzhana [The Ministry of Internal Affairs of Turkey Published the Data about the Militants from Azerbaijan]. URL: http:/verelq.am/ ru/node/20324 (accessed 28 December 2017).

12. «Minchenko konsalting» predstavil doklad po problemam stran YUzhnogo Kavkaza [Minchenko Consulting Have Presented the Report on South Caucasus Countries]. Gazeta.ru. URL: https:// www.gazeta.ru/politics/2015/08/18_a_7694735.shtml (accessed 28 December 2017).

13. Otvetstvennost za podzhog v Rostove vzyali na sebya neoyazychniki s Ukrainy [The Neo-pagans from Ukraine Took on Responsibility for the Arson in Rostov]. IA REGNUM. URL: https://regnum.ru/news/ 2315581.html (accessed 30 September 2017).

14. Pashchenko I.V. «Islamskoe gosudarstvo» i radikalno-islamistskie sily na Severnom Kavkaze: novye ugrozy natsionalnoy bezopasnosti Rossiyskoy Federatsii [Islamic State and Radical Islamist Forces in the North Caucasus: New Threats to National Security of the Russian Federation]. Globalnye vyzovy sovremennosti i problemy ustoychivogo razvitiya YUga Rossii: materialy Mezhdunar. nauch-prakt. konf. [Global Challenges and Problems of Sustainable Development of the South of Russia: Materials of International Scientific-Practical Conference]. Nalchik, Izd-vo KBNTS RAN, 2015, pp. 44-47.

15. Pozhar v Rostove-na-Donu ustroili ukrainskie diversanty [The Fire in Rostov-on-Don Was Staged by Ukrainian Saboteurs]. Moskovskiy komsomolets. URL: https://www.kp.ru/daily/26721/ 3747259/ (accessed 30 September 2017).

16. Polyakov E.M. «Islamskoe gosudarstvo» (IGIL) kak determinant politicheskogo nasiliya na Severnom Kavkaze ['Islamic State' (ISIL) as a Determinant of Political Violence in the North Caucasus]. Panorama [View], 2015, vol. 19, pp. 73-78.

17. Sundiev I.Yu., Smirnov A.A., Kostin V.N. Informatsionno-propagandistskaya deyatelnost terroristicheskoy organizatsii «Islamskoe gosudarstvo Iraka i Levanta» [Outreach Activities of the Terrorist Organization 'Islamic State of Iraq and the Levant']. Biblioteka kriminalista. Nauchnyy zhurnal, 2015, no. 1 (18), pp. 208-218.

18. Tokarev A.A. Institutsionalizatsiya ukrainskogo natsionalizma: ideologicheskie razlichiya mezhdu partiyami «Svoboda» i «Pravyy sektor» [Institutionalization of Ukrainian Nationalism: the Ideological Differences between the Parties 'Svoboda' and 'Pravyy sektor']. Vestnik MGIMO universiteta, 2014, no. 6 (39), pp. 144-152.

19. Yarlykapov A.A. «Islamskoe gosudarstvo» (IG): vyzovy dlya Yuga Rossii ['Islamic State' (ISIL): Challenges for the South of Russia]. Religiya i politika na Yuge Rossii: aspekty vzaimodeystviya [Religion and Politics in the South of Russia: Aspects of Interaction]. Moscow, Nauchnoe obshchestvo kavkazovedov Publ., 2015, pp. 78-97. 


\section{ПОЛИТИЧЕСКИЕ НАУКИ И РЕГИОНОВЕДЕНИЕ}

\section{Information about the Author}

Anton V. Bredikhin, Candidate of Sciences (History), Advisor to the Director, Center of Security Studies, RAS, Garibaldi St., 21b, 117335 Moscow, Russian Federation, bredikhin90@yandex.ru,https://orcid.org/0000-0003-4097-3854

\section{Информация об авторе}

Антон Викторович Бредихин, кандидат исторических наук, советник директора, Центр исследования проблем безопасности РАН, ул. Гарибальди, 21б, 117335 г. Москва, Российская Федерация, bredikhin90@yandex.ru, https://orcid.org/0000-0003-4097-3854 